\title{
Property analysis and pretreatment of rice straw for energy use in grain
}

\author{
drying: A review \\ Foday Robert Kargbo, Junjun Xing, Yanlin Zhang
}

\begin{abstract}
College of Engineering and Technology, Huazhong Agricultural University, Wuhan, 430070, China ABSTRACT
\end{abstract}

Utilization of rice straw for energy use in grain drying has attracted considerable interest in many rice producing countries. However, performance of rice straw as fuel in grain drying is uncertain without information on the fundamental properties of the raw material. Rice straw has low quality feedstock primarily determined by a high ash content (10-17\%) as compared to wheat straw (around 3\%) and high silica content in ash in rice (SO2 is 75\%) and in wheat 55\%. On the contrary rice straw feedstock has relatively low total alkali content ( $\mathrm{Na2O}$ and $\mathrm{K} 2 \mathrm{O}$ comprise $<15 \%$ of total ash) whereas wheat straws have $<25$ alkali content in ash. Based on its slagging index, Rs 0.04, fouling index, RF 0.24 . Rice straw is not expected to have significant operating problems or different emission compared with wheat straw and Rice husk under similar operating condition. The purpose of this paper is to reveal some of those properties from literature and how they could be improved by pretreatment technologies. The two fundamental properties analyzed in this paper are calorific (heating) and density values, the pretreatment Technologies are sizing and compression. The literature reveals that both physical and chemical properties of rice straw are improved significantly by the pretreatment technologies.

Keywords: Rice straw, Heating Value, Bulk Density, Pretreatment, Grain drying, Sizing, Compression.

\section{INTRODUCTION}

Straw remains the primary source of energy for many people in most countries and accounts for $14 \%$ of the total energy consumption in the world (Matsumura, et al 2005).It can be used as fuel for cooking, drying agricultural produce, and stable bedding for animals or as a material in industrial processes (example paper making) (Biomass waste research group 1999).The exploitation of rice straw as renewable energy has gained momentum since the present energy crisis and global warming threat. In comparison with fossil fuel such as coal and oil still the dominant fuel in electricity and heat generation, often reveals inferior properties of straw. It is low grade with high volatile, low calorific and density values, is a bulkier fuel (with poorer handling and transportation characteristics), its fibrous nature and high content of alkali compounds could potentially causing slagging, fouling, and grate sintering this makes it difficult to handle, transport and store efficiently, a major constraint to its use as an energy source.

Pretreatment of rice straw has proved to increase both its physical and chemical properties thus, minimizing the associated costs of transport, handling, and storage. These applications concerned with improving combustion efficiency and reducing pollution emission. However, the pretreatment technologies must be especially efficient to compensate for the costs involved in straw collection, transport, handling and storage.

Determination of these physical and chemical properties is required before the utilization as biomass 
energy. It is against this backdrop that this paper explores the literature for information on these fundamental properties and pretreatment technologies of rice straw to provide a basis for understanding how pretreatment technologies have improved these properties for energy use in grain drying.

Calorific value: This is an important index indicates the useful energy content of straw as fuel. There are two calorific values: the high calorific (heating) value (HHV) and low calorific value (LHV). For most agricultural residues, the high heating values are about $15-17 \mathrm{MJ} / \mathrm{Kg}$, The high calorific value of rice straw is $15.3 \mathrm{MJ} / \mathrm{Kg}$ (Jenkins, et al 1998), this value is comparatively low to other biomass as shown in table (Table 1),this is because of the

High ash content of rice straw (10-17\%) compared to wheat straw (around 3\%) and high silica content in ash in rice (SO2 is 75\%), (Baxter LL, 1993).On the contrary rice straw feedstock has relatively low total alkali content ( $\mathrm{Na2O}$ and $\mathrm{K} 2 \mathrm{O}$ comprise $<15 \%$ of total ash) whereas wheat straws have $<25$ alkali content in ash (Baxter et al., 1996).

Based on its slagging index, Rs 0.04 , fouling index, RF 0.24 . Rice straw is not expected to have significant operating problems or different emission compared with wheat straw and rice husk under similar operating condition.

Table 2. Shows experimental high heating values (HHV) of different types of biomass

\begin{tabular}{lc}
\hline Biomass & High heating \\
value $\mathrm{MJ} / \mathrm{Kg}$ & \\
\hline Rice Straw & 15.3 \\
Rice husk & 17.5 \\
$\mathrm{Ha}$ & 17.1 \\
Wheat straw & 17.8 \\
Wood & 19.0 \\
\hline
\end{tabular}

Source: Jenkins and Ebeling (1985)

Bulk density: This is useful for evaluating packaging and storage techniques. Several disadvantages of using raw biomass as energy feedstock may be attributed to the low bulk density of the biomass (Purohit et al 2005). Rice straw has to be transported to the power plant site, a proportion that becomes more difficult over long distances and lack of good transport system due to the low density of rice straw. The bulk density of rice straw is a round $75 \mathrm{Kg} / \mathrm{m}^{3}$ for loose straws and $100-180 \mathrm{Kg} / \mathrm{m}^{3}$ in packed and bailed form. The low bulk density of rice straw restricts the amount that can be used as energy source because of the associated costs of handling, transport and storage.

Table 1. Shows densities of various forms of biomass.

\begin{tabular}{lc}
\hline $\begin{array}{l}\text { Form } \\
\left(\mathrm{Kg} / \mathrm{m}^{3}\right) \text { dry basis }\end{array}$ & Bulk density \\
\hline Loose & $20-40$ \\
Chooped & $40-80$ \\
Bales & $110-200$ \\
Moduled & $96-128$ \\
Hammer milled & $40-100$ \\
Cubed & $320-640$ \\
Pelleted & $560-720$
\end{tabular}

Source: Jenkins et al, 2004.

\section{Pretreatment Technologies:}

Many different pretreatment techniques seem to be available for rice straw in principle but Commercial use of rice straw for energy is still not found in many rice producing countries because of the associated costs and lack of incentives or benefits for farmers to collect the straw instead of burning it in the field which increases greenhouse emission and environmental pollution.

The sections below describe the principles procedures of the possible pretreatment technologies, their advantages and difficulties encountered in the use of rice straw.

Sizing: This involves the cutting of straw into smaller sizes to improve boiler efficiency. Rice straws are 
dried in the air for two weeks, the dried rice straws with length ranges from $70-140 \mathrm{~cm}$ are cut to sizes less than $50 \mathrm{~mm}$ ( $10-15 \mathrm{~mm}, 5-2 \mathrm{~mm}$, or $>2 \mathrm{~mm}$ ) at the inlet by the blade at the rotating knife holder of a homemade machine (grinding or hammer mills) preparation of rice straws for co-firing in a boiler requires reducing the material to smaller sizes to increase the energy conversion efficiency and combustion performance .Large particles biomass feedstock such as palm shell and wood chips could provide a boiler efficiency of about $70 \%$ while the small size biomass such as rice husk, cut straw, and sawdust could provide boiler efficiency of $75 \%$.(Omori $\mathrm{H}, 2006$, Atchison, 1996).

It is usually not practical and not necessary to bring the biomass feedstock to the same size and shape as coal .However large and spherical biomass particles cause challenges for fuel conversion efficiency such sizes would cause an incomplete combustion of biomass.

Fine sized straws (5-2mm) improve the combustion behaviour. However, large sizes $(10-5 \mathrm{~mm})$ of biomass do not adversely affect the combustion performance. This technology is not commercially used and or not feasible in most rice producing countries because of the costs related and unavailability of simple straw cutting or sizing machines.

Compression: This is done to produce homogenous fuel with a high energy density in square, rectangle, cubed shapes with dimension of $50 \times 50 \times 50 \mathrm{~mm}^{3}$ (Loo Van $S$ et al.,2004a).Using a manual operation hot press with the maximum capability of compressing the solid fuel. Fig 3 shows different shapes of compressed rice straws. This compression technique increases the bulk density as well as the calorific value of the straw which has an impact on transportation costs as well as the required storage space in comparison with other biomass material and it can restrict the co- firing ratio due to limited capacity of boiler impact system.

The moisture content of the raw material before entering the compression press must be $12-17 \%$ w.b and it is essential not to exceed these values (European Biomass Association et al.,2000).If the material is too dry, the surface of the material may carbonize and the binders will burn before the process is finished, whereas if the material is too wet, then the moisture contained in the pressing cannot escape, and enlarges the product volume, making it mechanically weak (Loo Van S et al.,2004b).

Challenges related to this technique include problems during uploading and unloading of the pellets as they can be sensitive to mechanical damaging because they can absorbed moisture from the surrounding and can swell, loose shape, and consistency causing handing problems (Livingston,2005).

Pellets should be stored in closed halls or rooms, silo, bunkers, plastics and airtight zip bags (dry conditions) and storage times should be minimized to prevent absorbing atmospheric moisture. Pellets may be distributed in bags for small-scale applications. In case of co-firing however, the bulk material supply is necessary (Bergman et al., 2005).

The compressed rice straws can either be used alone or mixed with other biomass material (Co-firing) in direct combustion where air is injected into the combustion chamber to ensure that the biomass is completely burned in the combustion chamber. 
Agric. Biol. J. N. Am., 2010, 1(3): 195-200

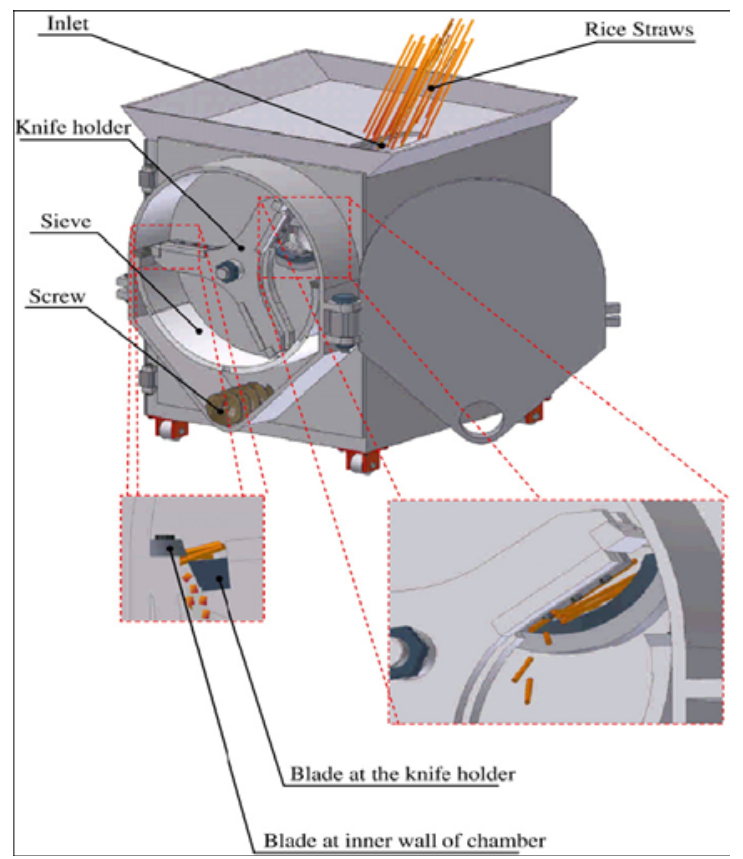

Fig 1 shows the schematic of a homemade machine used to size straw.

Source: shii Chou, et al, (2009)

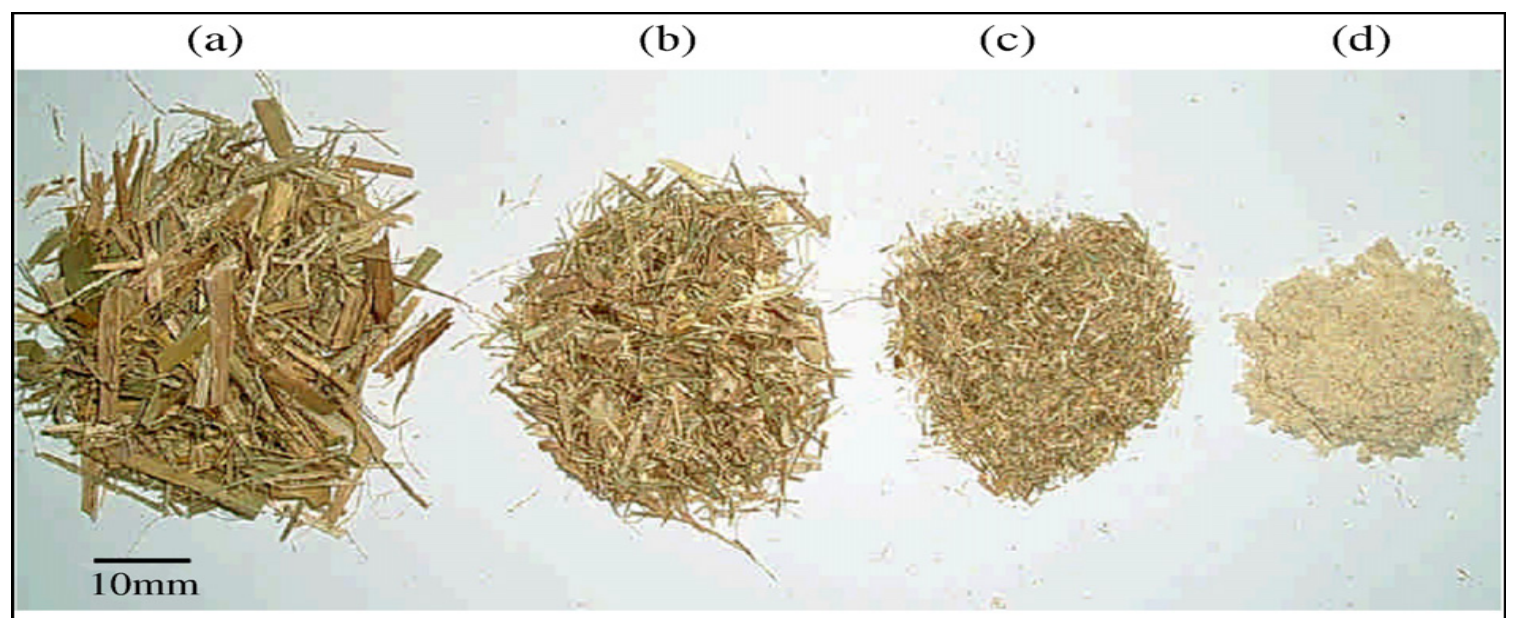

Fig. 2. (a) cut rice straw with the size of $10-5 \mathrm{~mm}$, (b) cut rice straw with the size of 5-2 $\mathrm{mm}$, (c)cut rice Straw with the size $2 \mathrm{~mm}$.

Source: shii chou,et al,(2009) 


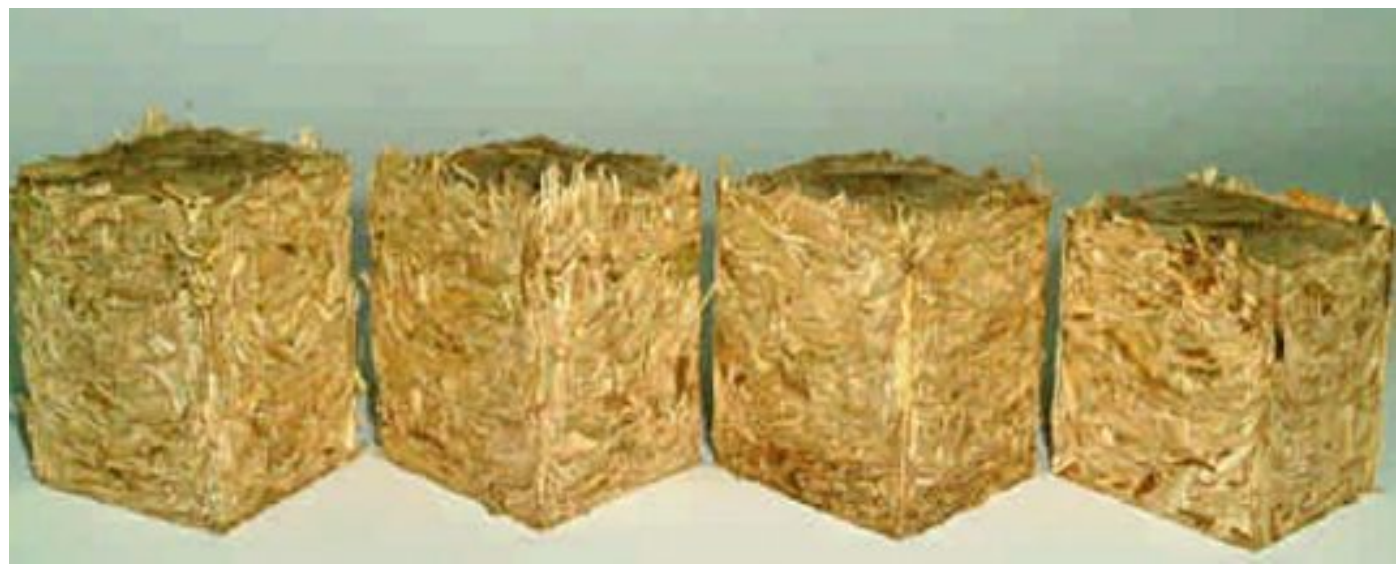

Fig. 3 Images of compressed rice straws.

Source: shii chou,et al,(2009)

\section{SUMMARY AND CONCLUSION}

Rice straw could be used with the current heat and power technologies in many rice producing countries to replace fossil fuels to reduce sulphure dioxide and greenhouse emission as well as prevent pollution from rice straw open burning. Determination of its physical and chemical properties is required before the ultilation as biomass energy to reduce the associated costs of transport, handling and storage which is a major hurdle with respect to its chemical and energy production.

Rice straw has low calorific value and low bulk density compared with other biomass. However, rice straw properties do not significantly impact process performance and do not have significant emission of chlorinated organic compounds and NOx compared with wheat straw and rice husk under the same operation conditions. Reduction of rice straws to smaller sizes can be necessary or beneficial. The shorter the size of the straw is cut, the higher the density in storage and in bales. This also increases the feedstock quality of the straw and hence it's heating value.

Compression of rice straw to homogenous fuel, improves the energy conversion efficiency and combustion performance of the straws. It also improves the bulk density of the straw

Thus, reducing the associated costs of transportation, handling, and storage. Pretreatment Technologies therefore improve the properties of rice straw to an attractive fuel in grain drying.

Although detail economic consideration and analysis of these technologies are not mentioned in this paper however, the discussion from this paper could be used for further work involving economic analysis of these pretreatment techniques to encourage rice straw utilization to avoiding open burning in rice producing countries and could be applied for research on other agricultural residues which is beyond the scope of this paper.

\section{REFERENCES}

Atchison JE (1976). Agricultural residue and other non wood plant fiber science.

Baxter LL (1993). Ash deposition during biomass and coal combustion.

Baxter L, Miles TR Jr., Miles TR, Jenkins BM (1996). Alkali disposition found in biomass boilers.

Bergman PCA, Boersma AR, Zwart RWR, Kiel JHA (2005).Palletizing for biomass co-firing in existing coal-fired power stations.

Biomass waste recycle group,(1999) status quo and problems for recying biomass waste in Japan. 
European Biomass Association (2000). http://www.engergyagency.at/(en)/publ

Jenkins BM (1998). Physical properties of biomass. In biomass Handbook, Chap.5.2, O. kitani and C. W. Hall, Gordon and Breach, New York.

Jenkins BM, Ebeling JM (1985).Correlation of physical and chemical properties of terrestrial biomass with conversion

Livingston WR (2005). A review of the recent experience in Britain with the co-firing of biomass with coal in large pulverized coal-fired boilers.

Loo VS (2004a). Handbook of Biomass combustion of co-firing.

Loo Van S, Koppejan J (2004b). Handbook of Biomass combustion of co-firing prepared by task 32 of the Implementing Agreement on Biomass under the auspices of the Int. Energy Agency; Tent University press.

Matsumura Y, Minowa, T and Yamamota,H (2005) Biomass and Bioenergy.Amount,Availability, and potential use of rice straw.

Omori H (2006). Biomass boiler manual. In: Proceedings off seminar reusing biomass waste in industrial boilers for energy recovery.

Purohit P; Tripathi A.K; Kandpal T.C (2005) Energetics of coal substitution by co-firing.

Shii C, Sheau H.L, Wen C (2009) Preparation and characterization of solid biomass fuel made from rice straw 